\title{
Is pharmaceutical expenditure related to the business cycles?
}

\author{
Carla Blazquez-Fernández*, David Cantarero-Prieto* and Marta Pascual-Saez* \\ *Department of Economics, Universidad de Cantabria. Avenue. Los Castros, s/n, \\ Santander CP 39005. Spain. E-mails: carla.blazquez@unican.es;
} david.cantarero@unican.es; marta.pascual@unican.es

\begin{abstract}
Recent research is focused on the study of health care expenditure and fiscal sustainability. In order to facilitate the understanding of this issue, we centre our interest on the Spanish pharmaceutical expenditure. Specifically, using data for the period 19952012, in the paper we analyse if economic cycles affect pharmaceutical expenditures. Our results support that there is a positive relationship between pharmaceutical expenditure and economic development. Therefore, we conclude that pharmaceutical expenditures are pro cyclical over the last years.
\end{abstract}

\section{Keywords:}

Pharmaceutical expenditures

Business cycles;

Health care system

Pro cyclical

\section{JEL Classification:}

H51, I1, I18 


\section{Introduction}

Rising trends of health expenditure during the past two decades and its link with health outcomes and Gross Domestic Product (GDP) has concerned policymakers (Worm, 2012). In Spain, as in other countries, health spending in general and pharmaceutical one in particular, have been a significant policy issue in health reform. This topic has received much research attention in several papers (Moreno-Torres et al., 2011; Kumar, 2013; Shi et al., 2014). However, new data available allow us to deep in the knowledge of these time trends.

Along total health care expenditure, the pharmaceutical one accounts for around a 20\% (OECD Health Statistics, 2014). More efforts need to be made in order to describe patterns and determinants of this expenditure for evidence-based policy making. This fact is particularly pertinent for the crisis period, because Spain has applied several austerity measures, among others, health expenditure cuts. Regarding pharmaceutical ones during the last years, policy makers have attempted to affect the prices or the volume of prescriptions in order to reduce final expenditures. Traditionally, they focused on the system of reference pricing, exclusion of pharmaceuticals from public financing, the promotion of generic drugs or incentives to improve prescribing practices. Using data from the OECD Health Statistics (2014) for the period 1995-2012, the aim of this study is to analyse if business cycles in Spain are concurrent to pharmaceutical expenditure.

The remainder of the paper is structured as follows. Section 2 provides a brief description of the data and an overview of the model specification. Section 3 presents the empirical results. The final section concludes.

\section{Data and empirical framework}

This study uses the OECD Health Statistics ${ }^{1}$ (2014), the main and largest available source of information to compare developed health care systems (Blázquez-Fernández

\footnotetext{
${ }^{1}$ It allows us doing benchmarking and international comparisons between different national health systems. Moreover, its frequency (annually renewable) and that it is used in a wide range of academic papers, support the reliability of this use.
} 
et al., 2013). Data set covers total per capita pharmaceutical health care expenditure (tpe) in Spain and its desegregation in public (pupe) and private (prpe) of Spain between 1995 and $2012^{2}$. Furthermore, data on per capita GDP is also used. Table 1 shows an overview of our key variables.

\section{[Insert Table 1. Here]}

Figure 1 plots the annual time trends of Total Pharmaceutical Expenditure (TPE), Total Health Expenditure (THE) and GDP. In this sense, we find that TPE and THE show a similar evolution as GDP. That is, an increase until the economic crisis period. However, TPE growth is lower than the one for THE. To describe the time trends of this issues, the annual TPE as a share of the THE was examined in Figure 2. Besides, to describe its growth in the contextual economic environment, the relationship between TPE, and THE, and GDP are also included. We can note that TPE/GDP is almost stable, whereas THE/GDP present a slightly increase. Regarding TPE/THE, it indicates a decrease during the study period. Moreover, Figure 3 presents the time trend of TPE and its desegregation by financing agent (public or private). It can be appreciated a similar evolution between these variables (all of them expressed in per capita \$US PPP), while private expenditure has much lower levels.

\section{[Insert Figure 1. Here] \\ [Insert Figure 2. Here] \\ [Insert Figure 3. Here]}

In order to estimate the cyclical sensibility of pharmaceutical health care expenditure, we follow Cleeren et al. (2015) in order to derive cyclical movement elasticities. In particular, we use the Hodrick-Prescott (HP) filter (1997) which decomposes time series in a trend and a cyclical component. We apply this to both series $^{3}$, tpe and $g d \mathrm{p}$. So, the basic empirical specification to be analysed is given by the following model:

$$
t p e_{t}^{c y c l e}=\beta g d p_{t}^{c y c l e}+\varepsilon_{t}
$$

\footnotetext{
${ }^{2}$ In order to ensure a complete time-series we disregarded the observations available prior 1995.

${ }^{3}$ Also, they were log-transformed before using the filter.
} 
where $\beta$ is the comovement elasticity. Its sign indicates if pharmaceutical expenditures are pro cyclical $(\beta>0)$ or countercyclical $(\beta<0)$.

Furthermore, to analyse the long-term consequences of the cyclical sensibility, we specified the following Equation:

$$
\Delta \text { tpe }_{t}^{\text {trend }}=\beta_{0}+\beta_{1} \text { contraction }_{t}+\beta_{2} \text { pupe }_{t}+\beta_{3} \text { prpe }_{t}+\varepsilon_{t}
$$

That is, through this Equation (2) we could analyse if the growth rate of our dependent variable is amplified when a decline occurs (contraction). So, the contraction

is a dummy variable that takes 1 when the economy is contracting ( $\Delta g d p_{t}^{\text {cycle }} \leq$ 0) and 0 otherwise (Lamey et al., 2012).

\section{Results}

Regarding how sensible are TPE to business cycles, the sign of the elasticity estimated through Equation (1) indicates that pharmaceutical expenditures behave pro cyclically and move in the same direction as the economy and business cycles. As for, if the cyclical sensibility have long-term permanent consequences, Table 2 reports the results for Equation 2 (the R-squared is 0.914). Our results indicate that pharmaceutical expenditures are not just a contraction phenomenon. Meanly, because the variable contraction is not significant while the intercept it is. Moreover, it can be appreciated how whereas public pharmaceutical expenditures are not significant, the private ones are (they are negative and significant). Multiple factors could explain this variability in cyclical sensibility. Perhaps, how population/patient health care needs are satisfied plays a major role to understand it.

\section{[Insert Table 2. Here]}

\section{Conclusions}

This paper contributes to recent empirical studies regarding health care expenditures, what are the determinants and how to control them. In particular, this is devoted to the analysis of the pharmaceutical ones for the Spanish case. In doing so, data from the 
OECD Health Statistics (2014) for the period 1995-2012 are taken. Results indicate that the economic cycles in Spain affect pharmaceutical expenditure in a pro cyclical way. That is, in this country, total pharmaceutical expenditures would increase during expansions and decrease during economic contractions. However, it is also shown that this cyclical sensibility does not have long-term permanent consequences.

For a policy economic perspective, this paper encourages some debates about the sustainability of national health care systems. In addition, it points out some consequences that public policies may have. So, control escalation of pharmaceutical expenditure is a key for a successful health system reform and to ensure access to medicines for all the patients. Nevertheless, as pharmaceutical costs continue rising drug design should be based on a value-based approach instead of a cost-management one.

\section{References}

Blázquez-Fernández， C., González-Prieto， N., Moreno-Mencía, P. (2013) Pharmaceutical expenditure as a determinant of health outcomes in EU countries, Estudios de Economía Aplicada, 31(2), 379-396.

Cleeren, K., Lamey, L., Meyer, J.H., De Ruyter, K. (2015) How Business Cycles Affect the Healthcare Sector: A Cross-country Investigation, Health economics, in Press.

Hodrick, R.J., Prescott, E.C. (1997) Postwar U.S. business cycles: an empirical investigation, Journal of Money, Credit, and Banking, 29(1), 1-16.

Kumar, S. (2013) Systems GMM estimates of the health care spending and GDP relationship: a note, The European Journal of Health Economics, 14(3), 503506.

Lamey, L., Deleersnyder, B., Steenkamp, J. B. E., Dekimpe, M. G. (2012) The effect of business-cycle fluctuations on private-label share: what has marketing conduct got to do with it? Journal of Marketing, 76(1), 1-19.

Moreno-Torres, I., Puig-Junoy, J., Raya, J.M. (2011) The impact of repeated cost containment policies on pharmaceutical expenditure: experience in Spain, The European Journal of Health Economics, 12(6), 563-573.

OECD Health Statistics, 2014. http://www.oecd.org/els/health-systems/health-data.htm 
Shi, L., Yang, H. Y., Cheng, G., Meng, Q. (2014) Time trends and determinants of pharmaceutical expenditure in China (1990-2009), PharmacoEconomics, 32(3), 257-264.

Worm, C. (2012) The relationship between wealth and health: evidence from a world panel of countries, Economics Letters, 115(2), 175-176. 
Table 1

Variables definitions and descriptive statistics

\begin{tabular}{llcccc}
\hline \multicolumn{1}{c}{ Variable } & \multicolumn{1}{c}{ Definition } & Mean & S.D. & Min. & Max. \\
\hline \multirow{2}{*}{ tpe } & $\begin{array}{l}\text { Per capita total pharmaceutical health care expenditure. } \\
\text { Expressed in \$US Purchasing Power Parities (PPP) and } \\
\text { natural logarithms. }\end{array}$ & 5.98 & 0.29 & 5.43 & 6.33 \\
pupe & $\begin{array}{l}\text { Per capita public pharmaceutical health care expenditure. } \\
\text { Expressed in \$US PPP and natural logarithms. }\end{array}$ & 5.65 & 0.29 & 5.09 & 6.01 \\
prpe & $\begin{array}{l}\text { Per capita private pharmaceutical health care expenditure. } \\
\text { Expressed in \$US PPP and natural logarithms. }\end{array}$ & 4.71 & 0.31 & 4.19 & 5.06 \\
$g d p$ & $\begin{array}{l}\text { Per capita Gross Domestic Product. Expressed in \$US } \\
\text { PPP and natural logarithms. }\end{array}$ & 10.11 & 0.25 & 9.68 & 10.40 \\
\hline
\end{tabular}




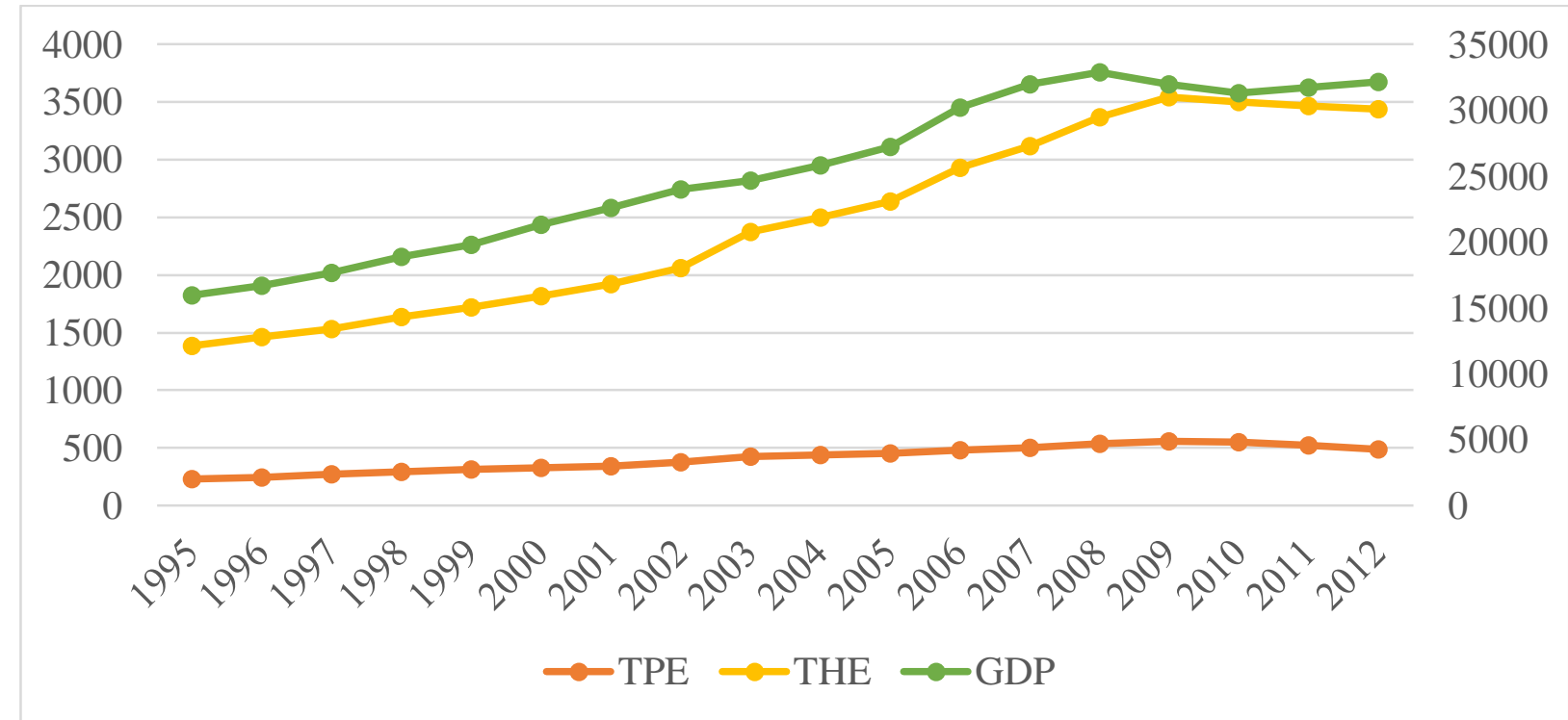

Notes: Left y-axis represents TPE and THE. Right y-axis represents GDP. Expressed in per capita \$US PPP.

Fig. 1. Time trends of TPE, THE and GDP over the years 1995-2012. 


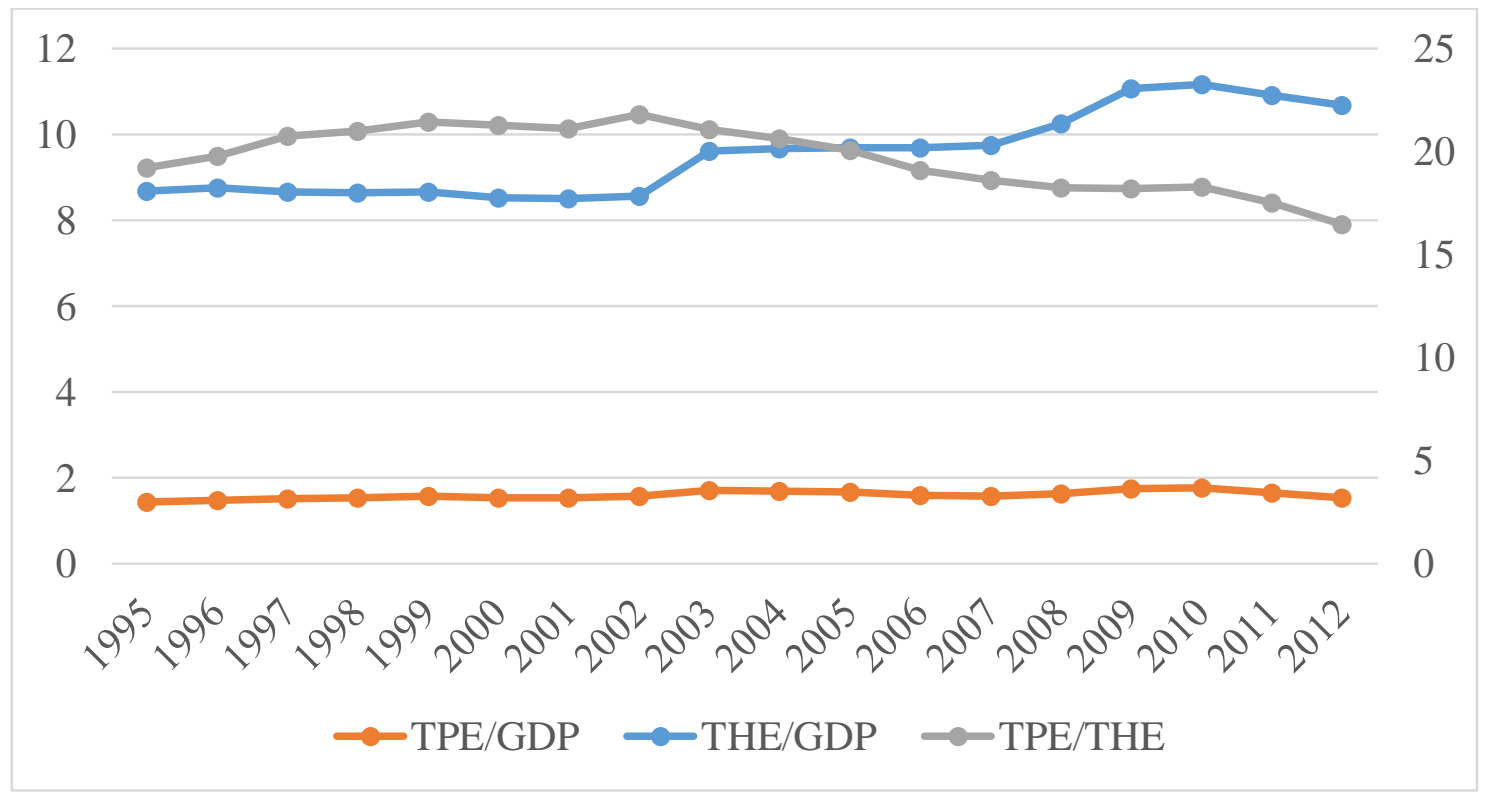

Notes: Left $y$-axis represents TPE and THE as a share of GDP. Right y-axis represents TPE/THE. Percentages $(\%)$.

Fig. 2. Time trends of TPE and THE as a share of GDP, and the TPE as a share of THE over the years 1995-2012. 


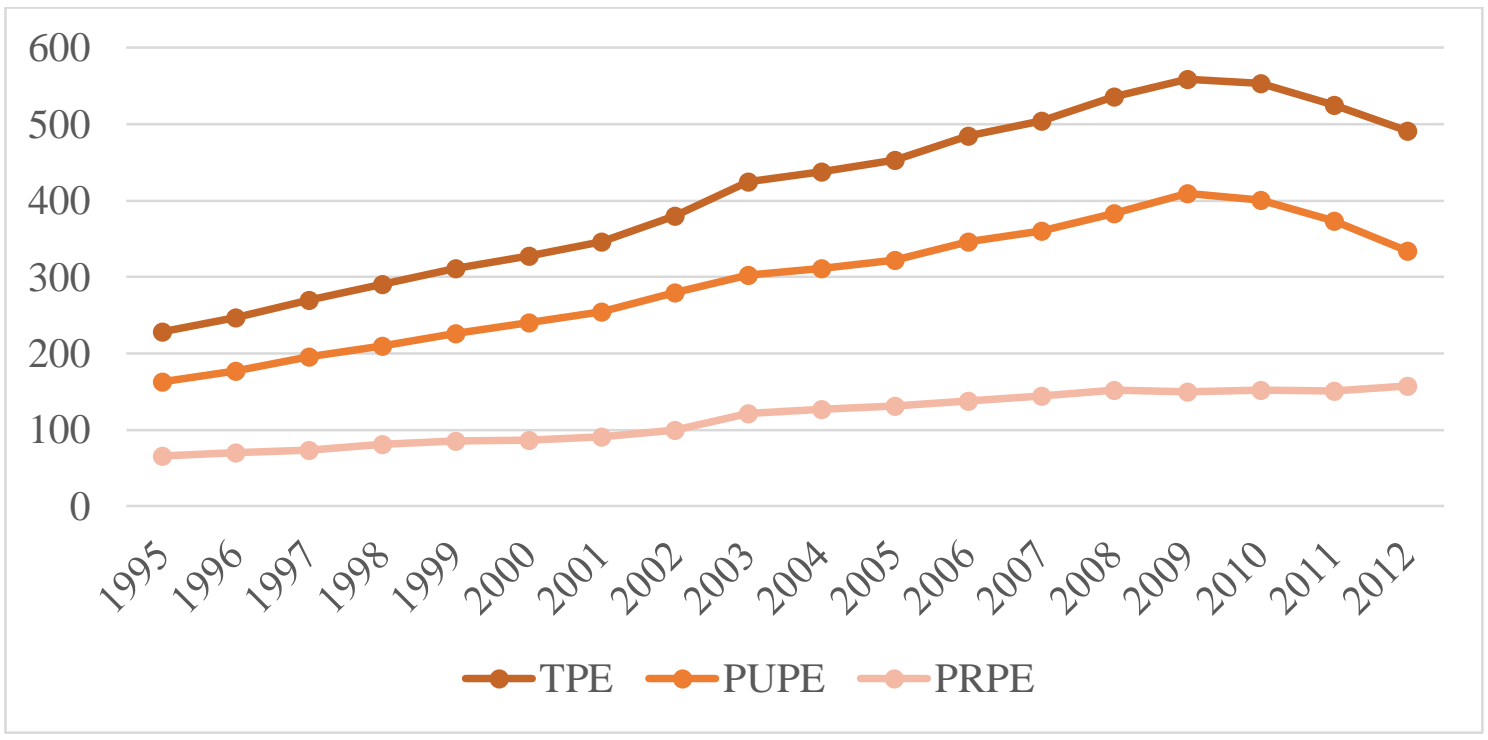

Fig. 3. Time trends of TPE per capita \$US PPP, by financing agent over the years 1995-2012. 
Table 2

Long-term consequences of cyclical sensibility. Dependent variable: $\Delta t p e_{t}^{t r e n d}$

\begin{tabular}{lrrrrrr}
\hline \multicolumn{1}{c}{ Independent variable } & \multirow{2}{*}{ Coefficient } & \multicolumn{2}{l}{ Std. error } & \multirow{2}{*}{ t } & \multirow{2}{*}{-value } & \multicolumn{2}{c}{ 95\% confidence interval } \\
& & & & & Lower & Upper \\
\hline intercept & 0.100 & 0.008 & 12.650 & 0.000 & 0.083 & 0.117 \\
contraction & 0.000 & 0.005 & -0.010 & 0.996 & -0.010 & 0.010 \\
pupe & -0.010 & 0.004 & -2.300 & 0.039 & -0.019 & -0.001 \\
prpe & -0.001 & 0.001 & -1.280 & 0.222 & -0.002 & 0.001 \\
\hline
\end{tabular}

Notes: ${ }^{* * * * *}$ and ${ }^{*}$ indicate significance at $1 \%, 5 \%$ and $10 \%$, respectively. 